ARTICLE

https://doi.org/10.1057/s41599-018-0210-9

\title{
Revising the eclipse prediction scheme in the Antikythera mechanism
}

\author{
Tony Freeth ${ }^{1}$
}

\begin{abstract}
In 1901, an extraordinary ancient Greek artefact was discovered in a shipwreck just off the tiny island of Antikythera. It was later shown to be a complex astronomical calculating machine and is now known as the Antikythera Mechanism. In 2005, it was established that it predicted eclipses, using a 7th century BC Babylonian eclipse cycle of 223 lunar months, known as the Saros Cycle. Understanding the complex eclipse prediction scheme on the Antikythera Mechanism has resulted from a fascinating series of discoveries. The eclipse prediction scheme is implemented through descriptive glyphs, inscribed round a 223-month Saros Dial at the rear of the Mechanism: a glyph in a particular month indicates a predicted eclipse. A 2008 publication deciphered the meaning of the glyphs: they indicate whether the predicted eclipse is lunar or solar; the possible visibility of the eclipse; and its time of day. The glyphs also include an alphabetical Index Letter, referring to inscriptions round the Saros Dial, which describe eclipse characteristics. In that publication, the full eclipse prediction scheme was not understood but subsequent work in 2014 made substantial progress. The eclipse characteristics, such as the colour and magnitude of the eclipse, are listed together in the inscriptions, together with a group of Index Letters for the eclipses to which they apply. The deeply puzzling grouping and ordering of these Index Letter Groups was solved with a simple mathematical model, which both explained these groups and the distribution of the glyphs round the Saros Dial-revealing an eclipse prediction scheme of extraordinary sophistication and ambition. Later work in 2016 proposed a radical revision of this eclipse prediction scheme, though it did not challenge the mathematical basis of the scheme. The 2016 scheme implied a completely different picture of the whole of the back plate of the Antikythera Mechanism, destroying its essential mathematical symmetry. This revision is comprehensively refuted here, except for the identification of a new text character in one of the Index Letter Groups, which implies an interesting revision of the 2014 scheme but which preserves the elegant 2014 reconstruction of the back plate of the Antikythera Mechanism.
\end{abstract}

\footnotetext{
${ }^{1}$ University College London (UCL), Mechanical Engineering, London, UK. Correspondence and requests for materials should be addressed to

T.F. (email: tony@images-first.com)
} 


\section{Introduction}

he Antikythera Mechanism was discovered by Greek sponge divers and taken to the National Archaeological Museum in Athens amongst a large array of ancient Greek artefacts. At the beginning, its significance was completely unrecognized-until it split apart some months later to reveal gearwheels, much to the astonishment of Museum staff. This led to years of study and controversy as its true nature emerged. After more than a century of research, much of this highly complex mechanism is now understood (e.g., Price, 1975; Wright, 2002, Wright, 2005, Wright, 2006, Freeth et al., 2006; Freeth et al., 2008, Jones, 2017). Major research advances resulted from a data gathering operation (Freeth et al., 2006), carried out in 2005 by an Anglo-Greek team of researchers in collaboration with the National Archaeological Museum in Athens and two high-tech scientific companies. A team from Hewlett-Packard (USA) used Polynomial Texture Mapping (PTM) (Malzbender and Gelb, 2006) (now commonly known as Reflectance Transformation Imaging) to examine the external surfaces of the fragments. Another team from X-Tek Systems (UK) (now part of Nikon Metrology) carried out X-ray Computed Tomography (X-ray CT) (Hadland et al. 2006) to gather high-resolution 3D X-ray data, revealing the internal features of the 82 surviving fragments of the Antikythera Mechanism.

\section{Eclipse prediction}

One surprising revelation from the new data was the discovery of thousands of text characters, hidden inside the fragments and unread for more than two thousand years. Much of our current knowledge about the Antikythera Mechanism has come from these inscriptions. A key result was the discovery that the Antikythera Mechanism predicted eclipses (or more strictly, eclipse possibilities) (Freeth et al., 2006). The eclipse prediction function is displayed on the Mechanism by a dedicated dial on the lower back plate of the device, based on the ancient Babylonian Saros Eclipse Prediction Cycle of 223 lunar months, which is just over 18 years. Further work (Freeth et al., 2008) revealed that the Saros Dial and its associated inscriptions are an eclipse prediction scheme of great refinement-forecasting not only the occurrence of an eclipse in a particular month but also the time-of-day of the eclipse in hours and characteristics of the eclipse, such as magnitude and colour.

\section{Index Letter Groups}

The layout and modus operandi of eclipse prediction on the Antikythera Mechanism are shown in Fig. 1.

The predictions of eclipse possibilities are distributed around the four-turn spiral dial as glyphs in the month cells of the 223month Saros scale. These indicate predictions of lunar and solar eclipses and sometimes both in that month. The Saros pointer slides at the hub end, as a pin in the end of the pointer follows the spiral groove between the scales (Freeth et al., 2006, Anastasiou et al., 2014). This means that the end of the pointer indicates a specific month round the dial. In months where there is a glyph, the content of the glyph indicates the type of eclipse-lunar or solar, as well as the eclipse time. $\Sigma$ stands for $\Sigma \mathrm{E} \Lambda \mathrm{HNH}$ (the goddess of the Moon), indicating a lunar eclipse; $\mathrm{H}$ stands for $\mathrm{H} \Lambda \mathrm{IO} \Sigma$ (the god of the Sun), indicating a solar eclipse. The anchor-like symbol is a ligature of $\omega$ and $\rho$, abbreviating $\omega \rho \alpha$ (hour), which is followed by a letter for a number of hours: this shows the time of day of the eclipse (Freeth et al., 2008).

The length of each Saros Cycle is about 6,583 1/3 days: the $1 / 3$ day adds about $8 \mathrm{~h}$ to the time of each repeat eclipse. This is accommodated in the Antikythera Mechanism by a dedicated subsidiary dial inside the Saros Dial, the Exeligmos Dial, which is illustrated in Fig. 1. The dial is divided into three sectors, which show eclipse time additions of 0,8 and $16 \mathrm{~h}$ and has a period of just over 54 years (three Saros cycles).

How were the types and positions of the glyphs determined?. A key feature of the glyphs is that they include an alphabetic Index Letter (Freeth et al., 2008). This means that the number of glyphs in the gaps left by lack of data can be calculated because the index letters need to conform to the Greek alphabet. From this it can be deduced that there were fewer solar predictions than lunar predictions (Freeth et al., 2006). This was explained by reference to a proposal by Claudius Ptolemy (2nd century AD) that, for a Northern observer, there is an asymmetry in the observability of solar eclipses that depends on whether they occur North or South of the lunar node (Freeth et al., 2008; Toomer, 1984). The distribution of the predictions in the glyphs was then attributed to a simple asymmetric distance from node principle, which produced a scheme that was consistent with the index letters and matched the surviving evidence (Freeth et al., 2008).

The glyphs are indexed by two alphabets: the first is the usual 24 letters of the Greek alphabet; the second is the same, except that the letters have bars on top (indicated in this paper by subscript 2 for typographical reasons.) Since there were almost certainly 51 glyphs in all (Freeth, 2014), this leaves three additional glyphs that need to be indexed. Previous research (Freeth, 2014) has proposed that this was done with three extraalphabetical characters, which follow the first two alphabets. These are the index letters for Glyphs 213, 214 and 219. The first of these Index Letters is referred to as ' 2 ' (because the character looks just like the numeral ' 2 ') and the other two are referred to here as ' 3 ' and ' 4 '-though, of course, it is assumed that the original characters looked nothing like ' 3 ' and ' 4 '.

\section{Index Letter Groups}

The index letter in each glyph is included in a unique group of index letters in the eclipse inscriptions that surround the dial. On the right side of Fig. 1, these Index Letter Groups are underlined in white and have white line numbers: they occur in Lines 9, 18, 29 and 36. They all reference solar eclipse inscriptions (Freeth, 2014). The user finds the Index Letter Group that contains the letter and then reads the lines of inscriptions above to discover the characteristics of the eclipse. The text and its translation show the characteristics that the scheme is designed to predict and are illustrated in Fig. 2.

The entire system poses a number of basic questions. How were the types and positions of the glyphs determined? What was the underlying principle behind the grouping and ordering of the index letters into Index Letter Groups? What are the consequences for the layout of the Back Plate of the Antikythera Mechanism?

Underlying principle behind the Index Letter Groups. The Index Letter Groups are written in a non-alphabetic ordering, which was for a long time very perplexing. An understanding of their organization was published in Freeth (2014). The explanation is an application of a signed distance from node principle, which distinguishes whether the distances from node are North (positive) or South (negative) of the ecliptic. Distance from node can be regarded as a surrogate measure for ecliptic latitude, since the Moon's orbit is inclined at just over $5^{\circ}$ from the ecliptic: if we know the nodal distance, we can calculate the ecliptic latitude. So, the Index Letter Groups correspond to bands of ecliptic latitude of the Moon at eclipse-analogous to clima in the ancient Greek description of geographic latitude. The ecliptic latitude of the 


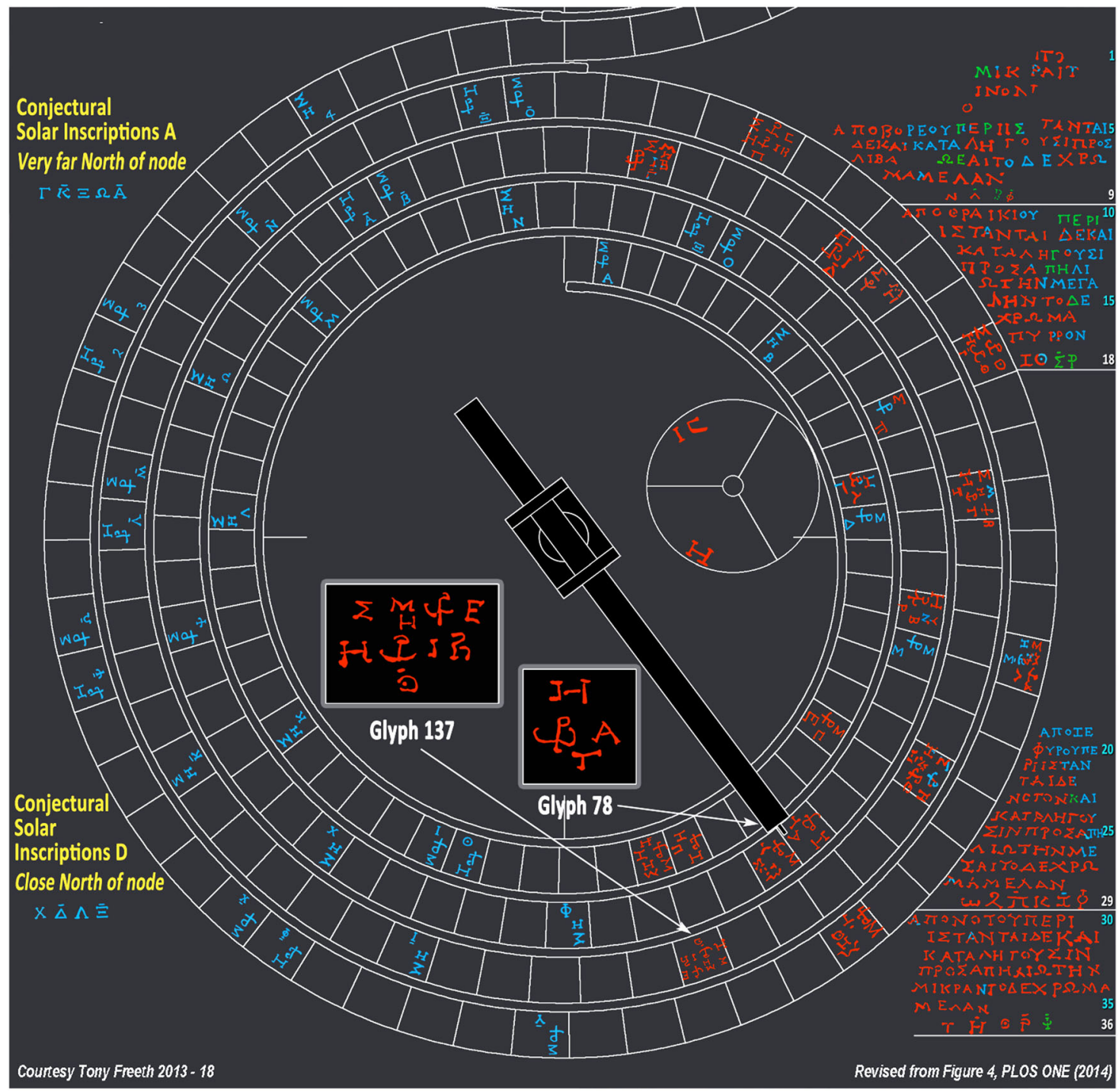

Fig. 1 The 223-lunar month Saros Dial. Text in red is traced from data; blue reconstructed from context; green is uncertain. Eclipse predictions-strictly speaking predictions of eclipse possibilities (EPs) - are specified by glyphs, numbered by their month round the dial: two examples are inset. The revisions advocated in the discussion below have been incorporated into this graphic: an extra text character at the beginning of L.29 and the move of X from L.18 to Conjectural Solar Inscriptions D. This figure is covered by the Creative Commons Attribution 4.0 International License. Reproduced with permission of Tony Freeth; copyright (C)2013-18 Tony Freeth, all rights reserved

Moon at eclipse largely determines the character of the eclipse. The resulting Eclipse Year Model (EYM) (Freeth, 2014) explained both the distribution of the glyphs round the Saros Dial and the structure of the Index Letter Groups. The key idea is to calculate the distance of each eclipse from the node point, North or South of the ecliptic. The node points are defined as the points in the eclipse year when the Sun is at one of the Moon's nodes (Freeth, 2014). In the following, the Eclipse Year Unit $(\mathrm{EYu})$ is defined so that there are $38 \mathrm{EYu}$ in each lunar month, which means that there are $446 \mathrm{EYu}$ in each Eclipse Year, because there are 19 Eclipse Years in a 223-month Saros period (Freeth, 2014). This makes all the mathematics remarkably simple, using only whole numbers. These units are not known from ancient astronomy, though any other unit chosen to express closeness to node-such as degrees or days-would be equivalent but would add an awkward constant to the calculations. As described in Freeth (2014), there are precedents for using such artificial units in both Babylonian and Chinese astronomy. The EYM explains the structure of the Index Letter Groups and this is shown in Fig. 3.
In Fig. 3, EYM's predictions North of the node are first arranged in lunar month order, including: month number, index letter, EYu from eclipse year start, Ascending or Descending node and $E Y u$ from node point (NP EYu). Similarly, for predictions $A t$ the node/South of the node, with a negative sign attached to their NP EYu to match their negative ecliptic latitude (Freeth, 2014, Note S1). The predictions are then re-ordered by EYu from node point in descending order. This generates the observed Index Letter Groups (in red) and the ordering of the letters within each group (with one exception). It also shows how EYM completes the picture with two conjectural solar Index Letter Groups (in black). The resulting distribution for the solar Index Letter Groups is shown in Fig. 3.

The Index Letter Groups now made sense and it became clear that the eclipse predictions, both for lunar and solar eclipses, were written in order on the Back Plate from the furthest North of the Node to the furthest South. This gave rise to a persuasive picture of the organization of the Index Letter Groups and their associated inscriptions on the Back Plate of the Mechanism. The theory in Freeth (2014) leads to a reconstruction of the 
a

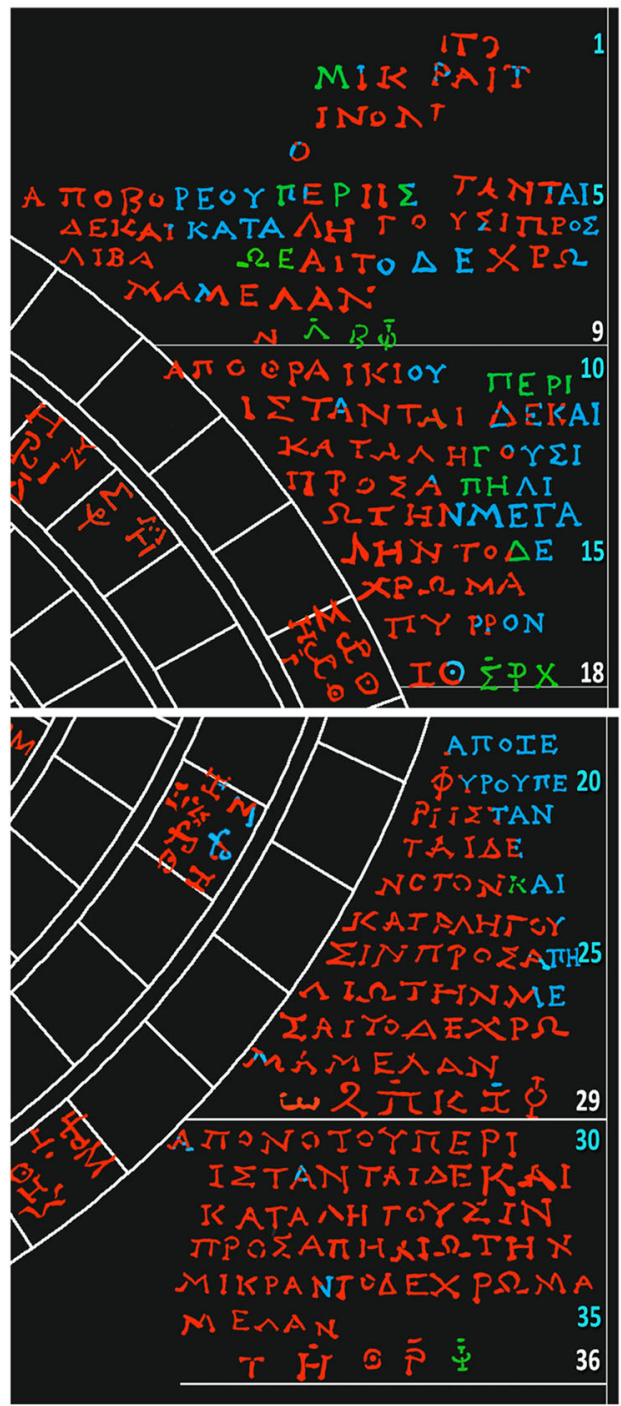

Courtesy Tony Freeth / Charles Crowther 2013 - 18 b

[- - - c.15 - - - -]ITO [ ....]

$[-\ldots$ c. 12 - - -]IKPAIT $[\ldots]$

$[-\ldots$ c. 10 - - ]INON vacat

$[-\ldots .0 .10--] 0$

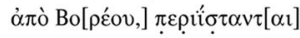

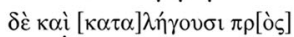

$\Lambda \hat{i} \beta \alpha[. .,] \Omega$ EAI, $\tau[\grave{o} \delta \grave{\varepsilon}] \chi \rho \hat{\omega}-$

$\mu \alpha \mu \varepsilon \dot{\lambda} \alpha \alpha v$.

$\mathrm{N}_{1} \Lambda_{2} \mathrm{~B}_{1} \Phi_{2}$

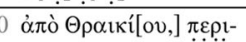

$1 \hat{i} \sigma \tau \alpha \nu \tau \alpha+\frac{1}{\delta} \kappa[\alpha i ̀]$

$\kappa \alpha \tau \alpha \lambda \eta \eta_{\gamma \circ}[v \sigma l]$

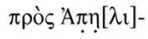

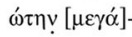

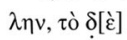

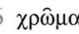

$\pi v \rho ̣ \rho$ [óv.]

$\mathrm{Z}_{1} \Theta_{2} \Sigma_{2} \mathrm{P}_{1} \mathrm{X}_{1}$

\section{$19[\dot{\alpha} \pi \grave{o} Z \varepsilon]-$}

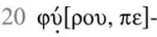

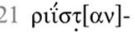

$22 \tau \alpha_{\iota} \dot{\delta} \dot{\varepsilon}$

23 Nótov $\kappa[\alpha i]$

$24 \kappa \alpha \tau \alpha \lambda \eta \dot{\gamma} \gamma \circ \mathrm{v}-$

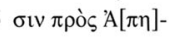

$26 \lambda$ เ

$\sigma \alpha 1, \tau o ̀ ~ \delta \grave{\varepsilon} \chi \rho \hat{\omega}-$

$\mu \alpha \mu \mu^{\prime} \lambda \alpha v^{2}$

$2942 \Pi_{2} K_{1} Z_{2} \Phi_{1}$

30 àrò Nótov, $\pi \varepsilon \rho 1-$

í

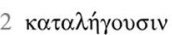

$\pi \rho \grave{\varsigma}{ }^{\prime} A \pi \eta \lambda \iota \dot{\omega} \tau \eta \nu$

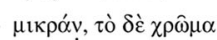

$35 \mu \dot{\varepsilon} \lambda \alpha$

$36 \mathrm{~T}_{1} \mathrm{H}_{2} \Theta_{1} \mathrm{P}_{2} \Psi_{2}$
C

small(?)

From the North, and they revolve

and end towards

the South-West, medium(?), and the

colour is black.

$\mathrm{N}_{1} \Lambda_{2} \mathrm{~B}_{1} \Phi_{2}$

From the North-North-West, and they

revolve and

end

towards the

East, large,

and the

colour is

red.

$Z_{1} \Theta_{2} \Sigma_{2} P_{1} X_{1}$

From the

West, and

they

revolve

southwards and

end

towards the

East, medium,

and the colour

is black.

$42 \Pi_{2} K_{1} Z_{2} \Phi$

From the South, and they

revolve and

end

towards the East,

small, and the colour is

black.

$\mathrm{T}_{1} \mathrm{H}_{2} \Theta_{1} \mathrm{P}_{2} \Psi_{2}$

Revised from Figure 8, PLOS ONE (2014)

Fig. 2 The solar eclipse inscriptions. a Text that is traced from the data is in red; uncertain text in green; text reconstructed from the context in blue. The Index Letter Groups, underlined in white and with white line numbers, refer to the lines of inscription above them. $\mathbf{b}$ Transcription using Leiden conventions. c Translation. The shared characteristics-such as magnitude and colour-are described in the lines above the Index Letter Groups. This figure is covered by the Creative Commons Attribution 4.0 International License. Reproduced with permission of Tony Freeth \& Charles Crowther; copyright (C2013-18 Tony Freeth/Charles Crowther, all rights reserved

missing Index Letter Groups and a conjectural reconstruction of the whole of the Back Plate, as shown in Fig. 4.

\section{Results}

The Freeth (2014) scheme produced a compelling picture of how the advanced eclipse prediction scheme was realized on the Back Plate of the Antikythera Mechanism. A radical revision of this scheme has been proposed in Anastasiou et al. (2016).

Anastasiou et al. (2016), Paper 4, p.197:

Our results confirm Freeth's proposal while also showing that his detailed reconstruction of the scheme of EP groupings and their rationale requires amendment.

'Requires' is a highly prescriptive word. Is this view justified? This paper argues that a small revision to the Index Letter Groups may be justified by the evidence, but this radical proposal is unfounded and lacking in credibility. This is not a minor issue, since the arrangement of the Index Letter Groups determines the whole layout of the eclipse inscriptions on the Back Plate. The proposal in Freeth (2014) is that the solar eclipse inscriptions were displayed round the Saros Dial and the lunar inscriptions round the Metonic Dial. In the Anastasiou et al. (2016) proposal, the solar eclipse predictions are displayed only to the right of the Saros Dial and the lunar eclipse inscriptions to the left of the Saros Dial and on both sides of the Metonic Dial. It is an unattractive breaking of the symmetry of the layout. There were more lunar glyphs (38) than solar glyphs (28) (Freeth et al., 2008) and Freeth (2014) conjectures that there were six solar Index Letter Groups and seven lunar Index Letter Groups. The lunar Index Letter Groups and associated inscriptions would certainly have fitted round the Metonic Dial, as proposed in Freeth (2014). They did not need three times as much space as those for solar-as suggested in Anastasiou et al. (2016). 
INDEX LETTER GROUPS - SOLAR

\begin{tabular}{|c|c|c|c|c|c|c|c|c|c|c|c|c|c|c|c|c|c|c|c|c|c|c|c|c|c|c|c|c|}
\hline $\begin{array}{l}\text { Para- } \\
\text { meters } \\
\end{array}$ & \multicolumn{3}{|c|}{$\begin{array}{l}\text { Lunar month } \\
\text { Month start }\end{array}$} & \multicolumn{2}{|c|}{$\begin{array}{r}38 \mathrm{EYu} \\
2 \mathrm{EYu} \\
\end{array}$} & \multicolumn{3}{|c|}{$\begin{array}{r}29.53 \text { days } \\
1.55 \text { days } \\
\end{array}$} & \multicolumn{4}{|c|}{$\begin{array}{l}\text { Desc. node at } \\
\text { Asc. node at }\end{array}$} & \multicolumn{2}{|c|}{$\begin{array}{r}66 \mathrm{EYu} \\
289 \mathrm{EYu} \\
\end{array}$} & \multicolumn{3}{|c|}{$\begin{array}{r}51.28 \text { days } \\
224.55 \text { days }\end{array}$} & \multicolumn{3}{|c|}{$\begin{array}{l}\text { Glyph } \\
\text { Limits }\end{array}$} & \multicolumn{2}{|c|}{$\begin{array}{r}\text { Lunar N } \\
\text { Lunar S } \\
\end{array}$} & \multicolumn{2}{|c|}{$\begin{array}{l}20 \mathrm{EYu} \\
20 \mathrm{EYu}\end{array}$} & \multicolumn{2}{|c|}{$\begin{array}{r}\text { Solar N } \\
\text { Solar S } \\
\end{array}$} & \multicolumn{2}{|c|}{$\begin{array}{r}20 \mathrm{EYu} \\
7 \mathrm{EYu} \\
\end{array}$} \\
\hline \multicolumn{21}{|c|}{ NORTH: month order } & \multicolumn{8}{|c|}{ AT/SOUTH: month order } \\
\hline Month & 0 & & 25 & 43 & 55 & 60 & 72 & 90 & 102 & 107 & 119 & 137 & & 154 & 166 & 172 & 184 & 201 & & & & 37 & 78 & 84 & 125 & 131 & 178 & 20 \\
\hline Index & $\mathrm{B}_{1}$ & $\Gamma_{1}$ & $\mathrm{Z}_{1}$ & $\Lambda_{1}$ & $\mathrm{~N}_{1}$ & $\Xi_{1}$ & $\mathbf{P}_{1}$ & $\mathbf{X}_{1}$ & $\Omega_{1}$ & $\mathrm{~A}_{2}$ & $\Delta_{2}$ & $\Theta_{2}$ & $\mathrm{~K}_{2}$ & $\Lambda_{2}$ & $\Xi_{2}$ & $\Pi_{2}$ & $\Sigma_{2}$ & $\Phi_{2}$ & 2 & 4 & $\Theta_{1}$ & $\mathrm{~K}_{1}$ & $\mathrm{~T}_{1}$ & $\Phi_{1}$ & $\mathrm{Z}_{2}$ & $\mathrm{H}_{2}$ & $\mathrm{P}_{2}$ & $\Psi_{2}$ \\
\hline Eyu & 266 & 10 & 20 & 258 & 268 & 12 & 22 & 260 & 270 & 14 & 24 & 262 & 272 & 16 & 26 & 254 & 264 & 18 & 28 & 256 & 248 & 30 & 250 & 32 & 252 & 34 & 36 & 24 \\
\hline Node & A & $\mathrm{D}$ & D & A & A & D & & $A$ & A & D & & & A & $\mathrm{D}$ & & A & A & & $\mathrm{D}$ & . & & & A & D & A & & D & A \\
\hline Eyu & 266 & 10 & 20 & 58 & 268 & 12 & 22 & 260 & 270 & 14 & 24 & 262 & 272 & 16 & 26 & 254 & 264 & 18 & 28 & 256 & -248 & -30 & -250 & -32 & -252 & -34 & -36 & -24 \\
\hline \multicolumn{21}{|c|}{ NORTH: descending order } & AT & \multicolumn{7}{|c|}{ SOUTH: descending order } \\
\hline & \multicolumn{5}{|c|}{$\begin{array}{l}\text { Conj. Solar Group A } \\
\text { Very far North of node }\end{array}$} & \multicolumn{4}{|c|}{$\begin{array}{c}\text { L. } 9 \text { Group } \\
\text { Far North of node }\end{array}$} & \multicolumn{5}{|c|}{$\begin{array}{c}\text { L. } 18 \text { Group } \\
\text { uite close North of node }\end{array}$} & \multicolumn{4}{|c|}{$\begin{array}{l}\text { Conj. Solar Group D } \\
\text { Close North of node }\end{array}$} & \multicolumn{5}{|c|}{$\begin{array}{l}\text { L. } 29 \text { Group } \\
\text { at node: North then South }\end{array}$} & \multicolumn{5}{|c|}{$\begin{array}{c}\text { L. } 36 \text { Group } \\
\text { Close South of node }\end{array}$} \\
\hline Month & 13 & 149 & 60 & 102 & 107 & 55 & 154 & 8 & 201 & 184 & 25 & 137 & 72 & 90 & 119 & 43 & 166 & 219 & 213 & 172 & 37 & 125 & 84 & 78 & 131 & 31 & 178 & 20 \\
\hline Index & $\Gamma_{1}$ & $\mathbf{K}_{2}$ & $\Xi_{1}$ & $\Omega_{1}$ & $A_{2}$ & $\mathrm{~N}_{1}$ & $\Lambda_{2}$ & $\mathrm{~B}_{1}$ & $\Phi_{2}$ & $\Sigma_{2}$ & $Z_{1}$ & $\Theta_{2}$ & $P_{1}$ & $\mathrm{X}_{1}$ & $\Delta_{2}$ & $\Lambda_{1}$ & $\Xi_{2}$ & 4 & 2 & $\Pi_{2}$ & $\mathrm{~K}_{1}$ & $\mathrm{Z}_{2}$ & $\Phi_{1}$ & $\mathrm{~T}_{1}$ & $\mathrm{H}_{2}$ & $\Theta_{1}$ & $P_{2}$ & $\Psi$ \\
\hline Eyu & 10 & 272 & 12 & 270 & 14 & 268 & 16 & 266 & 18 & 264 & 20 & 262 & 22 & 260 & 24 & 258 & 26 & 256 & 28 & 254 & 30 & 252 & 32 & 250 & 34 & 248 & 36 & 24 \\
\hline Node & D & $A$ & D & A & $D$ & A & D & A & D & A & D & A & D & A & D & $A$ & $D$ & $A$ & $D$ & A & D & A & D & A & D & A & $D$ & A \\
\hline NP Eyu & 20 & 19 & 18 & 17 & 16 & 15 & 14 & 13 & 12 & 11 & 10 & 0 & 8 & 7 & 6 & 5 & 4 & 3 & 2 & 1 & 0 & -1 & -2 & -3 & -4 & -5 & -6 & -7 \\
\hline
\end{tabular}

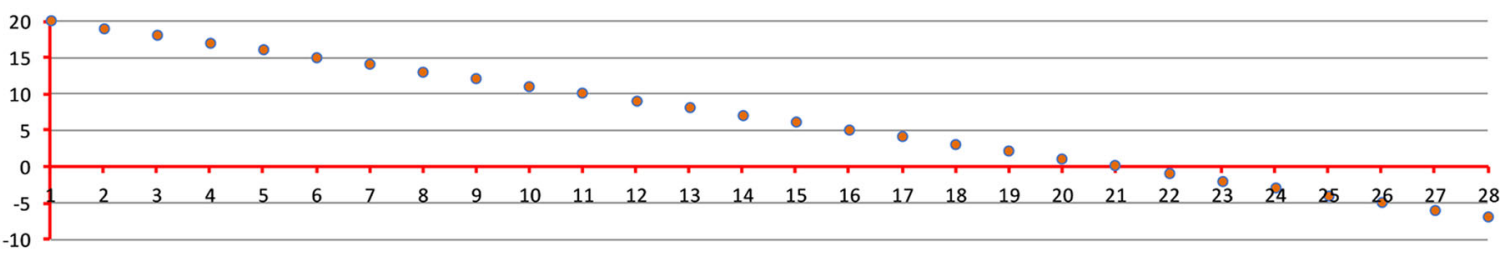

Courtesy Tony Freeth 2013

Reproduced from Figure 7, PLOS ONE (2014)

Fig. 3 Generation by EYM of the Index Letter Groups. Index Letters in red are those that are observed in the surviving glyphs; those in blue have not survived. The graph shows the distance from the node point in EYu for eclipse predictions in the re-ordered sequence. This figure is covered by the Creative Commons Attribution 4.0 International License. Reproduced with permission of Tony Freeth; copyright (C)2013-18 Tony Freeth, all rights reserved

First, the primary data and the technical arguments that challenge this revised scheme are addressed. It is necessary to challenge the Anastasiou et al. (2016) proposal in detail to explain why it is so deeply flawed.

Anastasiou et al. (2016, p. 193)

...Freeth (2014)...proposes an arrangement with the lunar paragraphs on the two sides of the Metonic Dial and the solar ones on the two sides of the Saros Dial. However, the first preserved paragraph straddles the line of division between the upper and lower halves of the Back Plate, so the arrangement we propose here appears preferable.

In fact, there is no problem with the first line of the eclipse inscription, as is evident in Fig. 4. So, it is not true that the Anastasiou et al. (2016) arrangement 'appears preferable' for this reason.

Anastasiou et al. (2016) challenges the scheme in Freeth (2014) in several important ways, claiming that:

1. Solar Glyph 149 does not exist.

2. The glyph indicated by the index letter $A_{2}$ should be in the L.9 Group.

3. Conj. Solar Group D should be amalgamated with the L.29 Group.

4. L.4 is a new Index Letter Group and the visible text character in L. 4 is $\omega$, not 0 .

5. The layout of the eclipse inscriptions on the back dial should be substantially altered.

These claims will be addressed in order. The first two proposed revisions are minor and will be dealt with quickly.

Solar Glyph 149 does not exist. The scheme calculated from the EYM model in Freeth (2014) proposes that Glyph 149 is $\Sigma, \mathrm{H}$ rather than just $\Sigma$, as in Freeth et al. (2008) and in Anastasiou et al. (2016)-in other words, Glyph 149 predicts both a lunar and a solar eclipse. In Anastasiou et al. (2016), p.183, Table 4.5, there are options for reconstructing the missing glyphs, based on ad hoc assumptions with little theoretical justification. By contrast, the Freeth (2014) scheme is based on a simple mathematical model, generated by elongation from the node point, which is the key factor that determines whether an eclipse occurs. Freeth (2014) shows how the Index Letter Groups are based on this model, with the addition of a +ve or -ve sign to indicate whether the eclipse is North or South of the node. It therefore seems natural and logical that the distribution of glyphs round the Saros Dial should also be based on the same model. The solution of the problem of the Index Letter Groups shows that all the necessary calculations of nodal distances must have been made. So, these calculations can be used to determine the glyph distribution. The omission of solar Glyph 149 also has the unfortunate consequence that the complete arithmetic sequence of nodal elongations, shown in the bottom row of numbers in Fig. 3, is broken by the omission of the number 19 in the descending sequence of EYu distances from the node point. For these reasons, this paper rejects the omission of solar Glyph 149, as proposed by Anastasiou et al. (2016).

The glyph indicated by the index letter $A_{2}$ should be in the L.9 Group. This is the second of the assertions in Anastasiou et al. (2016), which needs to be challenged. For typographic reasons, the index letters that include a top bar are indicated with a subscript ' 2 '. The great difficulties of interpreting the text in Line 9 from the available data are illustrated in Fig. 5.

Please see Data Availability at the end of this paper for access to the original PTM data.

The readings of the Index Letter in the eclipse inscriptions determine the Index Letter Groups. The index letters in Line 9 of the eclipse predictions are in a very damaged part of the plate and are hard to read. In Freeth (2014), Figure S6, the following identifications were made: 


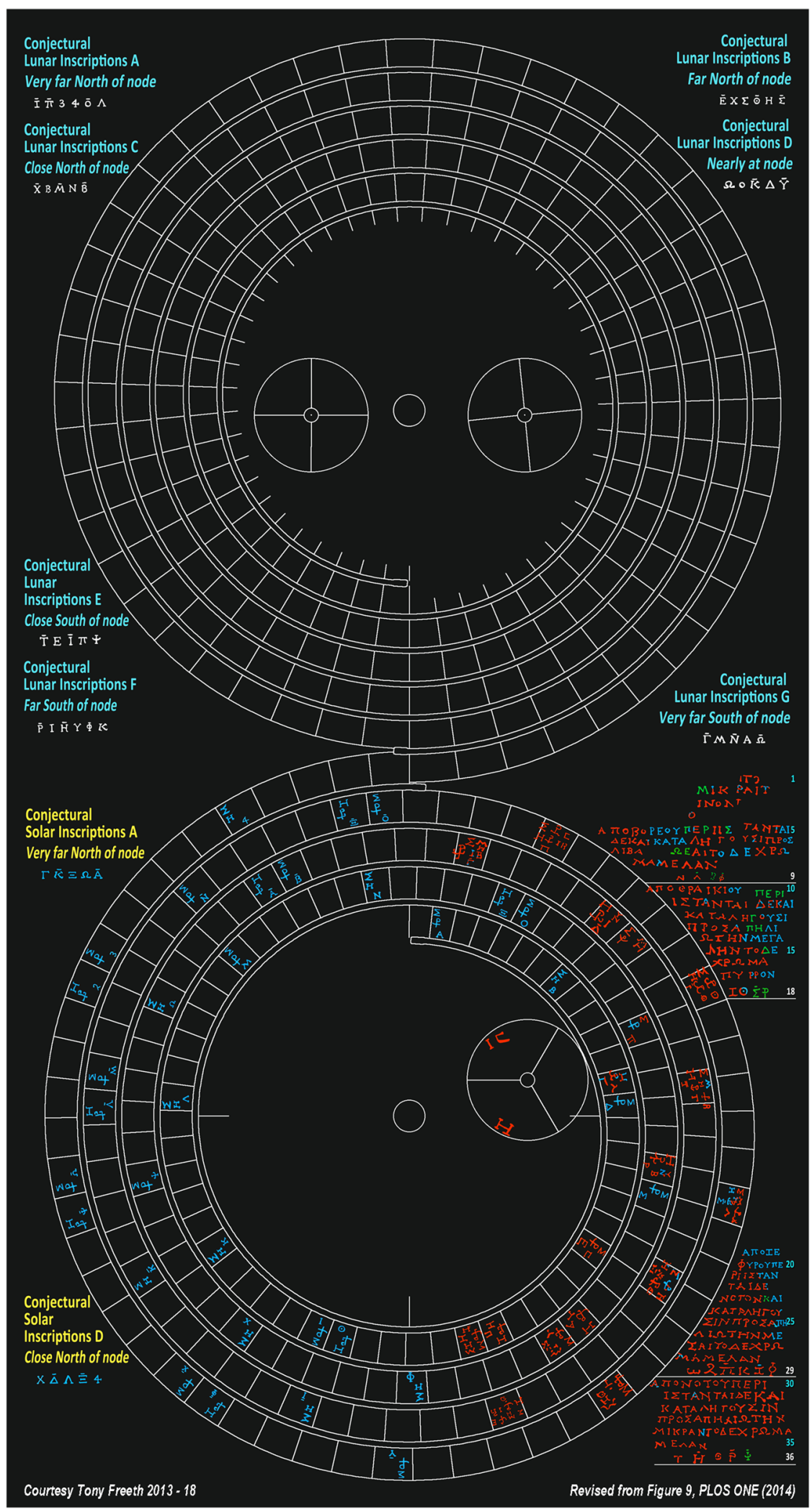

Fig. 4 Conjectural arrangement of Back Plate inscriptions. Text that is traced from the data is in red; text reconstructed from the context in blue; uncertain text in green. The Index Letter Groups, underlined in white and with white line numbers, refer to the lines of inscription above them. Conjectural lunar and solar inscriptions and Index Letter Groups are shown on the left-hand side and in the top-left corner, where direct evidence has not survived. This figure is covered by the Creative Commons Attribution 4.0 International License. Reproduced with permission of Tony Freeth; copyright (C2013-18 Tony Freeth, all rights reserved 

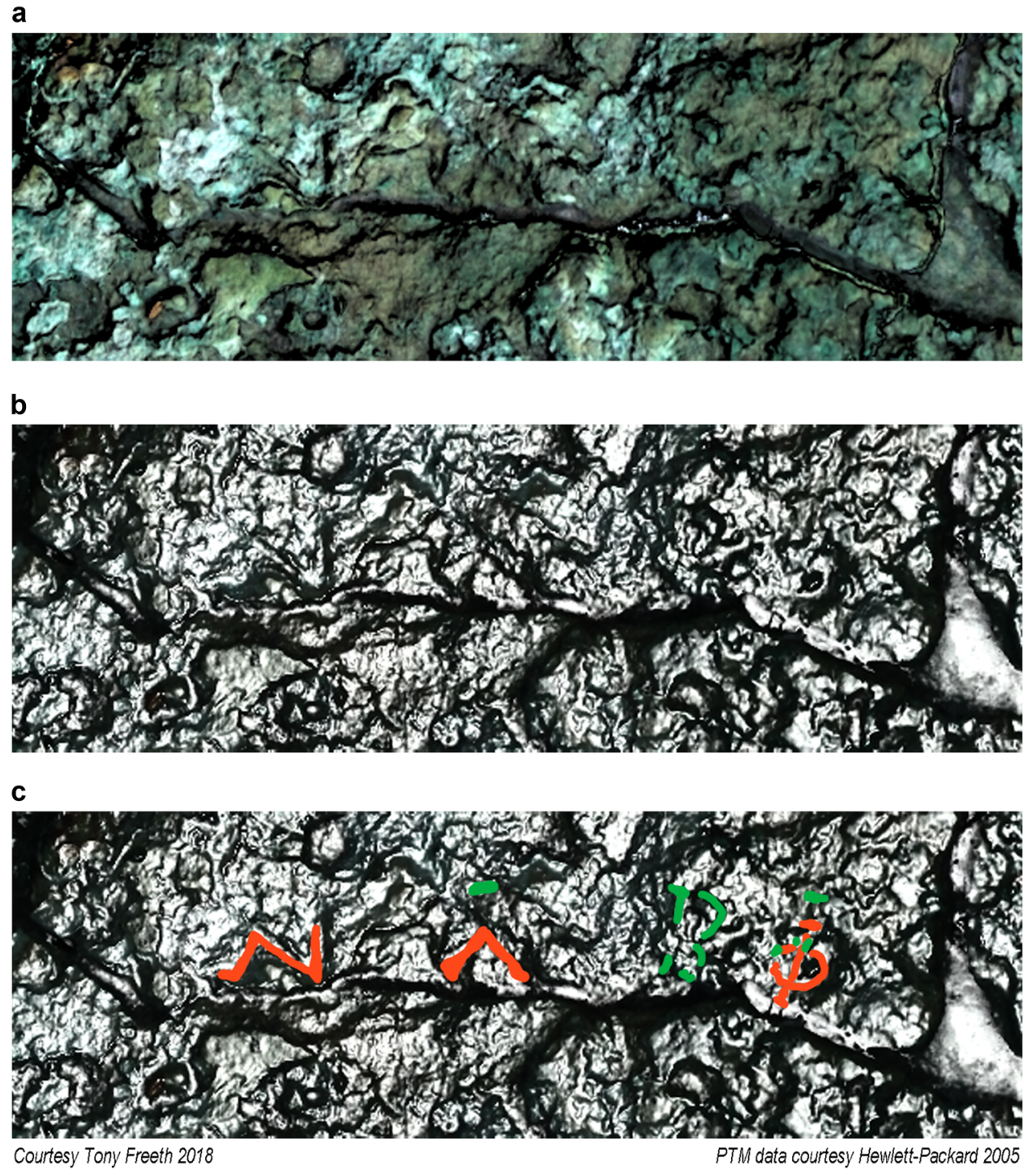

Fig. 5 Antikythera Eclipse Inscriptions: Index Letters Line 9. a PTM AK49a with diffuse gain. b PTM AK49a with specular enhancement. c Index letters superimposed. Red is traced from the data. Green is uncertain. In this reading, the Line 9 Index Letters are $\mathrm{N}_{1}, \Lambda_{2}, \mathrm{~B}_{1}, \Phi_{2}$. The character $\mathrm{N}$ is 1.5 mm high. This figure is covered by the Creative Commons Attribution 4.0 International License. Reproduced with permission of Tony Freeth \& Hewlett-Packard; copyright (C2005-18 Tony Freeth/Hewlett-Packard, all rights reserved

$\mathbf{N}_{1}$ is definite. $\boldsymbol{\Lambda}_{\mathbf{2}}$ and $\mathbf{B}_{1}$ would have been difficult to identify without EYM: they are certainly plausible, but only if you are looking for these characters. $\boldsymbol{\Phi}_{2}$ is convincing but still uncertain.

With the benefit of new readings of the PTM data using specular enhancement, this can be extended to a definite $\Lambda$ with an uncertain bar and confidence in $\Phi$, again with an uncertain bar. Anastasiou et al. (2016) suggests that there is an A to the left of the observed letter $\mathrm{N}$ in L.9. The X-ray CT is in general not very helpful for this line due to limitations of the X-ray scan resolution. When viewed under interactive lighting conditions enabled by PTM, it is difficult to make out even a hint of A, as Anastasiou et al. (2016) suggests. In any case, this proposal would simply mean that the first Index Letter Group, Conjectural Group $A$, has one less letter and the second group L.9 Group has one more. The Anastasiou et al. (2016) suggestion is not convincing enough to warrant this marginal change, so it has not been incorporated into the revised scheme of this publication-see the scheme later, Revised Freeth (2014).
Conj. Solar Group D should be amalgamated with L.29 Group. The third of the assertions in Anastasiou et al. (2016) is that two Index Letter Groups should be amalgamated-otherwise there will not be enough room in this scheme for all the index letters. The major change in Anastasiou et al. (2016) is the amalgamation of Conjectural Solar Group D with the L.29 Group. The first argument for this is based on observations of the X-ray CT of Fragment F.

Anastasiou et al. (2016, p.167):

Freeth does not mention any traces to the left of the barred pi. In fact, to the left of the pi, three further engraved letters are present, the first (approximately aligned with the beginning of line 28) apparently an apical letter, i.e., alpha, delta, or lambda, with no visible bar, the second a probable lambda, and the third a probable xi of the old form with a vertical crossing the middles of the three horizontal strokes (as also found in the Front Cover Inscription where xi is a numeral). 

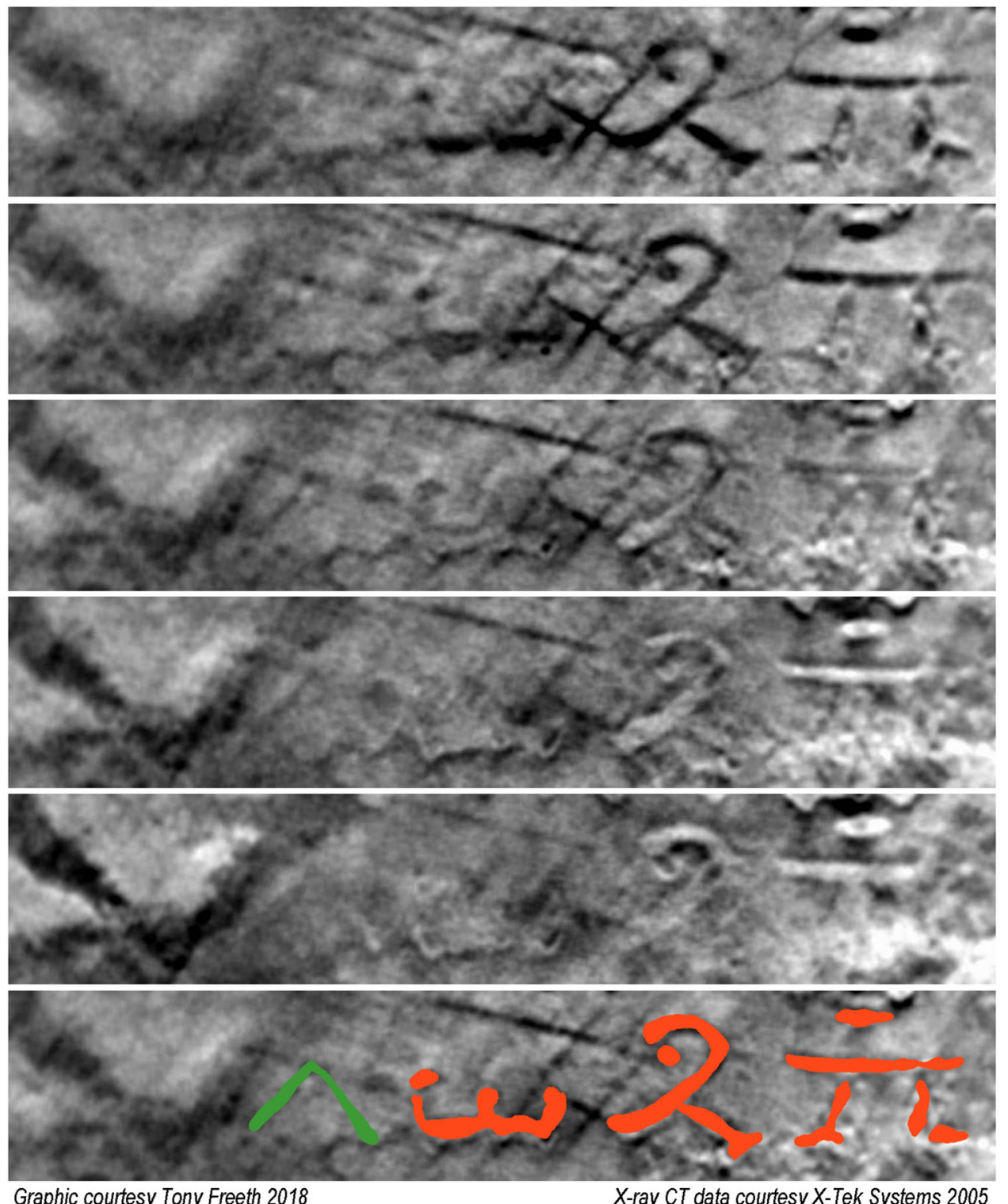

Graphic courtesy Tony Freeth 2018

X-ray CT data courtesy X-Tek Systems 2005

Fig. 6 X-ray CT slices through Fragment F, showing the left side of Line 29 of the Antikythera eclipse inscriptions. The images are parallel X-ray CT slices, spaced at intervals of $0.08 \mathrm{~mm}$ ( 80 microns) and oriented in the plane of the text. Red text is traced from the X-ray CT. Green text is uncertain. The character 2 is $2.5 \mathrm{~mm}$ high. This figure is covered by the Creative Commons Attribution 4.0 International License. Reproduced with permission of Tony Freeth \& X-Tek Systems; copyright (C2005-18 Tony Freeth/X-Tek Systems, all rights reserved

Presumably, the phrase '...to the left of the barred pi...' is an oversight. The authors mean '...to the left of the symbol $2 . .$. '. One of the claims is that, to the left of this symbol, there is an additional character that is read in Anastasiou et al. (2016) as $\Xi$. The paper then continues by suggesting two additional characters to the left of this purported $\Xi$, which are read as $\Delta$ and $\Lambda$. The problem is that, though there probably is an extra character to the left of 2, it is almost certainly not $\Xi$ and the other two characters do not seem to exist.

The evidence from the X-ray CT. Let us examine the X-ray CT data, shown in Fig. 6.

The reading of the data to the left of 2 is a critical issue for establishing the Line 29 Index Letter Group. It is difficult to give a true impression of the totality of the data in a single image stack of X-ray CT slices. To definitively identify a text character, it is often necessary to examine many slices and to change the angle as well as the brightness and contrast of the slices. So, the summary below should be read as a commentary on the totality of the data, partially illustrated here by a stack of X-ray CT slices. Please see Data Availability at the end of this paper for access to more X-ray data.

The text characters 2 and $\Pi_{2}$ are very clear through all the layers. In the top layers we see the direct image: the text is black against the background plate, showing where the metal was removed by the engraving tool, so there is no X-ray density and the text looks black. In the bottom layers, we see the image in the accretion layer, where the shape of the letter has been filled by an accretion, which has taken the form of the text characters and has hardened over time into a separate layer. The text is lightcoloured against the background because the hard accretion has $\mathrm{X}$-ray density. The surfaces of the plates are covered in many accidental marks, which sometimes appear as if they might be text -for example the criss-cross marks to the left of 2 in Fig. 6. An effective test to check if a mark is actual text is to observe whether the mark persists through the layers from direct to accretion 
image. It is also typical that the accretion layer has subsequently moved slightly away from the original engraved marks. In the case of 2, measurements in the X-ray CT show that the accretion layer is about $0.2 \mathrm{~mm}$ lower than the original text character.

As is suggested in Anastasiou et al. (2016), there does appear to be the remains of a character immediately to the left of 2 -as can be seen in Fig. 6. This was not reported in Freeth (2014). It not only appears as a direct image but also as an accretion image. Like the character 2, this accretion image is also shifted around $0.2 \mathrm{~mm}$ downwards. All of this indicates that it is a genuine part of a text character, rather than an accidental mark. In Anastasiou et al. (2016), p.167, this character is claimed to be $\Xi$ and is described as '...of the old form with a vertical crossing the middles of the three horizontal strokes....'. To complete this proposed $\Xi$, we would need a stroke at the top and a stroke in the middle as well as the vertical crossing. Referring to Fig. 6, the stroke at the top in the $\mathrm{X}$-ray CT images is clearly an accidental scratch: it is much too long for the top stroke of a $\Xi$; it is at the wrong angle; and it does not persist into the accretion layer. So, there is no evidence of the conjectured top stroke of $\Xi$. There is evidently no middle stroke. The supposed 'vertical crossing' goes barely one third up the proposed $\Xi$. It is almost certain that this character is not $\Xi$. Though the character looks somewhat like a lower case $\omega$, this does not make sense in terms of the Index Letter Groups. It is far more likely to be a new extra-alphabetical character, as we would expect from Fig. 3, where it is designated as the notional symbol 4: the Index Letter of the last glyph on the Saros Dial. In Fig. 6, the definite parts of the character have been traced in red. There are suggestions of some uncertain parts of the character, but these are so indefinite that no attempt has been made to trace them. This character has not yet been identified from other classical texts after an extensive search-so any suggestions about its identity would be appreciated. There is no physical evidence of the other extra-alphabetical character, denoted by 3 , either in the glyphs or in the inscriptions.

To the left of the purported $\Xi$, Anastasiou et al. (2016) suggest additional characters $\Delta$ and $\Lambda$. Again, the Anastasiou et al. (2016) scheme needs to cram in more index letters into the Line 29 Group, since there would not be any room for them elsewhere in this scheme. There are several diagonal strokes in both directions here-as there are in many places throughout the rest of the X-ray CT slices. Throughout the plates of the Antikythera Mechanism, there are random marks, which have sometime been wrongly identified as text. The possibility is examined here that these suggested text characters are in fact actual text. No credible traces of the $\Delta$ proposed in Anastasiou et al. (2016) have been found by this author. All the marks in this area appear to be accidental and have no persistence into the accretion layer. There are possible traces of the $\Lambda$ suggested in Anastasiou et al. (2016), as can be seen in Fig. 6. This is very uncertain, since it appears to exist in the accretion layer only: a fairly sure sign that it did not originally exist as a text character. So, it has not been incorporated into the revised Index Letter Groups in this paper. If $\Lambda$ does exist, then this would in any case need only a minor change of the Index Letter Groups, whereby $\Lambda$ is moved from Conjectural Solar Group $D$ to the L.29 Group.

What are these text characters?. There has been much speculation as to the identity of the character 2 and the other unidentified extra-alphabetic characters. 2 is the first extraalphabetical character, used to index Glyph 213 (Freeth, 2014). But what exactly is it? Since it does not appear to be a common character in Greek texts, this issue was aired on an epigraphic forum. There was only one positive response from Gregg
Schwendner (Wichita State University, USA)-as reported in Anastasiou et al. (2016, p.167):

...following a suggestion of Gregg Schwendner, we believe this was the numeral for 1000 (drawn as a notional alpha modified by a hooked stroke), though here functioning as a symbol supplementing the letters of the Greek alphabet.

We might then expect 3 to be hooked $B$ and 4 to be hooked $\Gamma$. It is hard to reconcile the X-ray data with the idea that 4 is hooked $\Gamma$. Could it possibly be hooked $\Omega$, as the last of the index letters? Gregg Schwendner advises that 'hooked' numerals only go as high as $\Theta$ (personal communication).

The implications of the Anastasiou et al. (2016) proposal. The logic of the Anastasiou et al. (2016) scheme leads to some very uncomfortable conclusions. For the sake of argument, let us accept the Anastasiou et al. (2016) sequence $\Delta \Lambda \Xi$ before 2. The most immediate problem is that there is no glyph with the index letter 4 immediately to the left of 2 , as there should be according to the Freeth (2014) theory of the formation of the Index Letter Groups. Anastasiou et al. (2016) comes up with a 'solution': all the additional glyphs-after the two standard alphabets of Index Letters (one barred) -in Months 213, 214 and 219-were indexed with the same symbol, notably 2 (Anastasiou et al. 2016). (Both Freeth (2014) and Anastasiou et al. (2016) support the idea that there were probably 51 glyphs in total.) The Anastasiou et al. (2016) proposal is hard to accept. Why would the designer do this? It breaks the natural common-sense idea that each glyph has its own unique index letter, which then refers to its relevant Index Letter Group in the eclipse inscriptions. It is incomprehensible that anyone would design the scheme in the way proposed in Anastasiou et al. (2016).

An immediate objection to the Anastasiou et al. (2016) proposal might be that the scheme would not work: the two solar glyphs in Months 213 and 219 might have very different nodal elongations-so they would need to be in different Index Letter Groups and the idea that they could share the same index letter would break down. In fact, the solar EPs in Months 213 and 219 are adjacent in terms of their distance from the node pointin other words, they can both be in the same Index Letter Group. Similarly, Glyphs 214, 219 are both lunar glyphs, which are adjacent in terms of their nodal elongations. They are in the same conjectural lunar Index Letter Group, as can be seen in Freeth (2014), Figure S11. So, we cannot reject the Anastasiou et al. (2016) scheme on this simple logic.

Different schemes for the Index Letter Groups. Different schemes for the structure of the Index Letter Groups are shown in Fig. 7.

There are 28 Index Letters in the Freeth (2014) scheme, Fig. 7a and our revised scheme, Fig. $7 \mathrm{c}$. There are 26 in the Anastasiou et al. (2016) scheme, Fig. 7b. This is because in this latter scheme Glyph 149 is not a solar glyph and because both Glyph 213 and Glyph 219 are indexed with the same symbol.

Even if we accept the identification of the index letters in Anastasiou et al. (2016) and the idea that all the final three glyphs on the Saros Dial were indexed with the same character 2, there are still overwhelming objections to the scheme. The distribution of the number of glyphs in the Index Letter Groups in Anastasiou et al. (2016) is 3-5-5-9-5, which is an oddly uneven distribution. If you were choosing bands of ecliptic latitude to define eclipse characteristics, this distribution of groups would be an inexplicable choice. In addition, in Fig. 7 (B), the discontinuity in the numbers in the bottom row is immediately apparent, with 19 
a: Index Letter Scheme: Freeth (2014)

\begin{tabular}{|c|c|c|c|c|c|c|c|c|c|c|c|c|c|c|c|c|c|c|c|c|c|c|c|c|c|c|c|}
\hline \multicolumn{18}{|c|}{ NORTH: descending order } & & & AT & \multicolumn{7}{|c|}{ SOUTH: descending order } \\
\hline \multicolumn{5}{|c|}{$\begin{array}{l}\text { Conj. Solar Group A } \\
\text { very far North of node }\end{array}$} & \multicolumn{4}{|c|}{$\begin{array}{l}\text { L. } 9 \text { Group } \\
\text { Far North of node }\end{array}$} & \multicolumn{5}{|c|}{$\begin{array}{c}\text { L. } 18 \text { Group } \\
\text { Quite close North of node }\end{array}$} & \multicolumn{4}{|c|}{$\begin{array}{c}\text { Conj. Solar Group D } \\
\text { Close North of node }\end{array}$} & \multicolumn{5}{|c|}{$\begin{array}{c}\text { L. } 29 \text { Group } \\
\text { Nearly at node: North then South }\end{array}$} & \multicolumn{5}{|c|}{$\begin{array}{c}\text { L. } 36 \text { Group } \\
\text { Close South of Node }\end{array}$} \\
\hline 13 & 149 & 60 & 102 & 107 & 55 & 154 & 8 & 201 & 184 & 25 & 137 & 72 & 90 & 119 & 43 & 166 & 219 & 213 & 172 & 37 & 125 & 84 & 78 & 131 & 31 & 178 & 207 \\
\hline$\Gamma_{1}$ & $\mathrm{~K}_{2}$ & $\Xi_{1}$ & $\mathbf{\Omega}_{1}$ & $\mathrm{~A}_{2}$ & $\mathrm{~N}_{1}$ & $\Lambda_{2}$ & $\mathrm{~B}_{1}$ & $\Phi_{2}$ & $\Sigma_{2}$ & $\mathrm{Z}_{1}$ & $\Theta_{2}$ & $P_{1}$ & $\mathrm{X}_{1}$ & $\Delta_{2}$ & $\Lambda_{1}$ & $\Xi_{2}$ & 4 & 2 & $\Pi_{2}$ & $\mathbf{K}_{1}$ & $\mathrm{Z}_{2}$ & $\Phi_{1}$ & $\mathrm{~T}_{1}$ & $\mathrm{H}_{2}$ & $\Theta_{1}$ & $\mathbf{P}_{2}$ & $\Psi_{2}$ \\
\hline 46 & 308 & 48 & 306 & 50 & 304 & 52 & 302 & 54 & 300 & 56 & 298 & 58 & 296 & 60 & 294 & 62 & 292 & 64 & 290 & 66 & 288 & 68 & 286 & 70 & 284 & 72 & 282 \\
\hline D & A & D & A & D & A & D & $A$ & D & $A$ & D & $A$ & D & A & D & $A$ & $\mathrm{D}$ & $A$ & D & A & D & $A$ & D & A & D & A & D & A \\
\hline 20 & 19 & 18 & 17 & 16 & 15 & 14 & 13 & 12 & 11 & 10 & 9 & 8 & 7 & 6 & 5 & 4 & 3 & 2 & 1 & 0 & -1 & -2 & -3 & -4 & -5 & -6 & -7 \\
\hline
\end{tabular}

b: Revised Index Letter Scheme: Anastasioiu et al. (2016)

\begin{tabular}{|c|c|c|c|c|c|c|c|c|c|c|c|c|c|c|c|c|c|c|c|c|c|c|c|c|c|c|}
\hline \multicolumn{19}{|c|}{ NORTH: descending order } & AT & \multicolumn{7}{|c|}{ SOUTH: descending order } \\
\hline \multicolumn{3}{|c|}{$\begin{array}{c}\text { L. } 4 \text { Group } \\
\text { Very far N. of node }\end{array}$} & \multicolumn{5}{|c|}{$\begin{array}{c}\text { L. } 9 \text { Group } \\
\text { Far North of node }\end{array}$} & \multicolumn{5}{|c|}{$\begin{array}{c}\text { L. } 18 \text { Group } \\
\text { Quite close North of node }\end{array}$} & \multicolumn{9}{|c|}{$\begin{array}{c}\text { L. } 29 \text { Group } \\
\text { Nearly at node: North then South }\end{array}$} & \multicolumn{5}{|c|}{$\begin{array}{c}\text { L. } 36 \text { Group } \\
\text { Close South of Node }\end{array}$} \\
\hline 13 & 60 & 102 & 107 & 55 & 154 & 8 & 201 & 184 & 25 & 137 & 72 & 90 & 119 & 43 & 166 & 219 & 213 & 172 & 37 & 125 & 84 & 78 & 131 & 31 & 178 & 207 \\
\hline$\Gamma_{1}$ & $\Xi_{1}$ & $\mathbf{\Omega}_{1}$ & $\mathbf{A}_{2}$ & $\mathbf{N}_{1}$ & $\Lambda_{2}$ & $\mathrm{~B}_{1}$ & $\Phi_{2}$ & $\Sigma_{2}$ & $\mathrm{Z}_{1}$ & $\boldsymbol{\Theta}_{2}$ & $\mathbf{P}_{1}$ & $\mathbf{X}_{1}$ & $\Delta_{2}$ & $\Lambda_{1}$ & $\Xi_{2}$ & 2 & 2 & $\Pi_{2}$ & $\mathrm{~K}_{1}$ & $\mathrm{Z}_{2}$ & $\Phi_{1}$ & $\mathrm{~T}_{1}$ & $\mathbf{H}_{2}$ & $\Theta_{1}$ & $\mathbf{P}_{2}$ & $\Psi_{2}$ \\
\hline 46 & 48 & 306 & 50 & 304 & 52 & 302 & 54 & 300 & 56 & 298 & 58 & 296 & 60 & 294 & 62 & 292 & 64 & 290 & 66 & 288 & 68 & 286 & 70 & 284 & 72 & 282 \\
\hline D & D & $A$ & $\mathrm{D}$ & $A$ & D & A & D & $A$ & D & A & $D$ & A & D & A & $D$ & $A$ & D & A & $\mathrm{D}$ & $A$ & D & $A$ & $\mathrm{D}$ & $A$ & D & A \\
\hline 20 & 18 & 17 & 16 & 15 & 14 & 13 & 12 & 11 & 10 & 9 & 8 & 7 & 6 & 5 & 4 & 3 & 2 & 1 & 0 & -1 & -2 & -3 & -4 & -5 & -6 & -7 \\
\hline
\end{tabular}

c: Revised Index Letter Scheme: this publication

\begin{tabular}{|c|c|c|c|c|c|c|c|c|c|c|c|c|c|c|c|c|c|c|c|c|c|c|c|c|c|c|c|}
\hline \multicolumn{20}{|c|}{ NORTH: descending order } & AT & \multicolumn{7}{|c|}{ SOUTH: descending order } \\
\hline \multicolumn{5}{|c|}{$\begin{array}{l}\text { Conj. Solar Group A } \\
\text { Very far North of node }\end{array}$} & \multicolumn{4}{|c|}{\begin{tabular}{|c|} 
L. 9 Group \\
Far North of node
\end{tabular}} & \multicolumn{4}{|c|}{$\begin{array}{c}\text { L. } 18 \text { Group } \\
\text { Quite close North of node }\end{array}$} & \multicolumn{4}{|c|}{$\begin{array}{l}\text { Conj. Solar Group D } \\
\text { Close North of node }\end{array}$} & \multicolumn{6}{|c|}{$\begin{array}{c}\text { L. } 29 \text { Group } \\
\text { Nearly at node: North then South }\end{array}$} & \multicolumn{5}{|c|}{\begin{tabular}{|c|} 
L. 36 Group \\
Close South of Node \\
\end{tabular}} \\
\hline 13 & 149 & 60 & 102 & 107 & 55 & 154 & 8 & 201 & 184 & 25 & 137 & 72 & 90 & 119 & 43 & 166 & 219 & 213 & 172 & 37 & 125 & 84 & 78 & 131 & 31 & 178 & 207 \\
\hline$\Gamma_{1}$ & $\mathbf{K}_{2}$ & $\Xi_{1}$ & $\mathbf{\Omega}_{1}$ & $\mathbf{A}_{2}$ & $\mathbf{N}_{1}$ & $\Lambda_{2}$ & $\mathrm{~B}_{1}$ & $\Phi_{2}$ & $\Sigma_{2}$ & $\mathrm{Z}_{1}$ & $\Theta_{2}$ & $P_{1}$ & $X_{1}$ & $\Delta_{2}$ & $\Lambda_{1}$ & $\Xi_{2}$ & 4 & 2 & $\Pi_{2}$ & $\mathbf{K}_{1}$ & $\mathrm{Z}_{2}$ & $\Phi_{1}$ & $\mathrm{~T}_{1}$ & $\mathbf{H}_{2}$ & $\Theta_{1}$ & $\mathbf{P}_{2}$ & $\Psi_{2}$ \\
\hline 46 & 308 & 48 & 306 & 50 & 304 & 52 & 302 & 54 & 300 & 56 & 298 & 58 & 296 & 60 & 294 & 62 & 292 & 64 & 290 & 66 & 288 & 68 & 286 & 70 & 284 & 72 & 282 \\
\hline $\mathrm{D}$ & A & $\mathrm{D}$ & $A$ & $\mathrm{D}$ & $A$ & $\mathrm{D}$ & $A$ & $\mathrm{D}$ & A & $\mathrm{D}$ & $A$ & $\mathrm{D}$ & $A$ & $\mathrm{D}$ & A & $\mathrm{D}$ & A & $\mathrm{D}$ & $A$ & $\mathrm{D}$ & A & $\mathrm{D}$ & $A$ & D & A & $\mathrm{D}$ & A \\
\hline 20 & 19 & 18 & 17 & 16 & 15 & 14 & 13 & 12 & 11 & 10 & 9 & 8 & 7 & 6 & 5 & 4 & 3 & 2 & 1 & 0 & -1 & -2 & -3 & -4 & -5 & -6 & -7 \\
\hline
\end{tabular}

Courtesy Tony Freeth 2013 - 18

Fig. 7 Schemes for the Index Letter Groups. In the second row in each table, text in red refers to index letters observed in the glyphs; text in blue to index letters that have not been observed. a The original scheme from Freeth (2014). b The proposed Index Letter Scheme from Anastasiou et al. (2016). c The revised scheme proposed in this publication. This figure is covered by the Creative Commons Attribution 4.0 International License. Reproduced with permission of Tony Freeth; copyright (C2013-18 Tony Freeth, all rights reserved

missing because Glyph 149 is not a solar glyph in the Anastasiou et al. (2016) Scheme.

L. 4 is an Index Letter Group and the visible text character in L.4 is $\boldsymbol{\omega}$ not o. The fourth claim in Anastasiou et al. (2016) is a fundamental problem. Anastasiou et al. (2016) proposes that the solar eclipse inscriptions were all to the right of the Saros Dial. One consequence of this is that, in the Anastasiou et al. (2016) scheme, Line 4 must constitute another Index Letter Group with associated inscriptions in Lines 1-3 above this group-otherwise, there is no place in the scheme for the index letters, which are Very Far North of Node, $\Gamma_{1}, \Xi_{1}, \Omega_{1}$. The lines are virtually unreadable and cannot be identified directly as describing eclipse characteristics-except possibly for the uncertain word small in Line 2 (Freeth, 2014; Anastasiou et al., 2016). The data that are relevant for determining this issue can be seen in Fig. 8 .

The only text visible in Line 4 is part of a single text character, which was interpreted as o in Freeth (2014). It certainly looks like o in both versions of the PTM, but the Anastasiou et al. (2016) theory needs another explanation:

Anastasiou et al. (2016, p.199):

We suggest that the clear but fragmentary trace of a single letter in line 4 was the right half of omega in its cursive (open-topped) form. 109

109 The cursive omega is not attested elsewhere in the Mechanism's inscriptions as a letter in its own right, but the symbol for $\dddot{\omega} \rho \alpha$ in the glyphs is based on this form.

The problem for the Anastasiou et al. (2016) Scheme is that it really needs this character to be $\Omega_{1}$. The eclipse inscriptions relating to the L.9 Index Letter Group start with L.5. So, in the Anastasiou et al. (2016) scheme L.4 must be the line for the index letters of the previous group and these, according to this scheme are $\boldsymbol{\Gamma}_{\mathbf{1}}, \boldsymbol{\Xi}_{\mathbf{1}}, \boldsymbol{\Omega}_{\mathbf{1}}$-the last character identified as lower case $\omega_{1}$ in the Anastasiou et al. (2016) scheme. The character in Line 4 in Fig. 8 cannot possibly be $\Gamma$ or $\Xi$ and it certainly does not look like upper case $\Omega$-so Anastasiou et al. (2016) asserts that it must surely be lower case $\omega$. The surface of the plate is missing to the left of the surviving traces of this character, so there is no evidence to establish the existence or absence of the left-half of the proposed $\omega$. In Figs. 8a, b, nearly the whole circle of $\mathrm{o}$ is visible. Figures $8 \mathrm{c}-\mathrm{f}$ show other instances of $\mathrm{o}$ in the eclipse inscriptions: some are created with a single continuous line and some in segments; many are not quite complete circles; all are of similar size. These examples are all consistent with the proposition that the character in L.4 is o: it is a typical variant of this character throughout the inscriptions. It is not convincing to read this as the right-hand side of $\omega$. In any case, this really does not seem to be a likely suggestion. In the Antikythera Mechanism all the observed index letters - 17 in the glyphs themselves and 12 in the Index Letter Groups-are upper-case letters. The Zodiac Dial and Parapegma inscriptions also include index letters and all of those that survive are upper-case (Freeth, 2014). In fact, all the known normal text characters in the Antikythera Mechanism-now numbering more than 3000-are upper-case letters (Freeth et al., 2006; Freeth et al., 2008). The only exception is a special character, the ligature of $\omega$ and $\rho$ that is an abbreviation for $\omega \rho \alpha$, meaning hour and showing the eclipse times in the eclipse prediction glyphs. For the Anastasiou et al. (2016) Scheme to work, we need to believe that just one of the known index letters was a lower-case $\omega$. This is not plausible. 
a

b

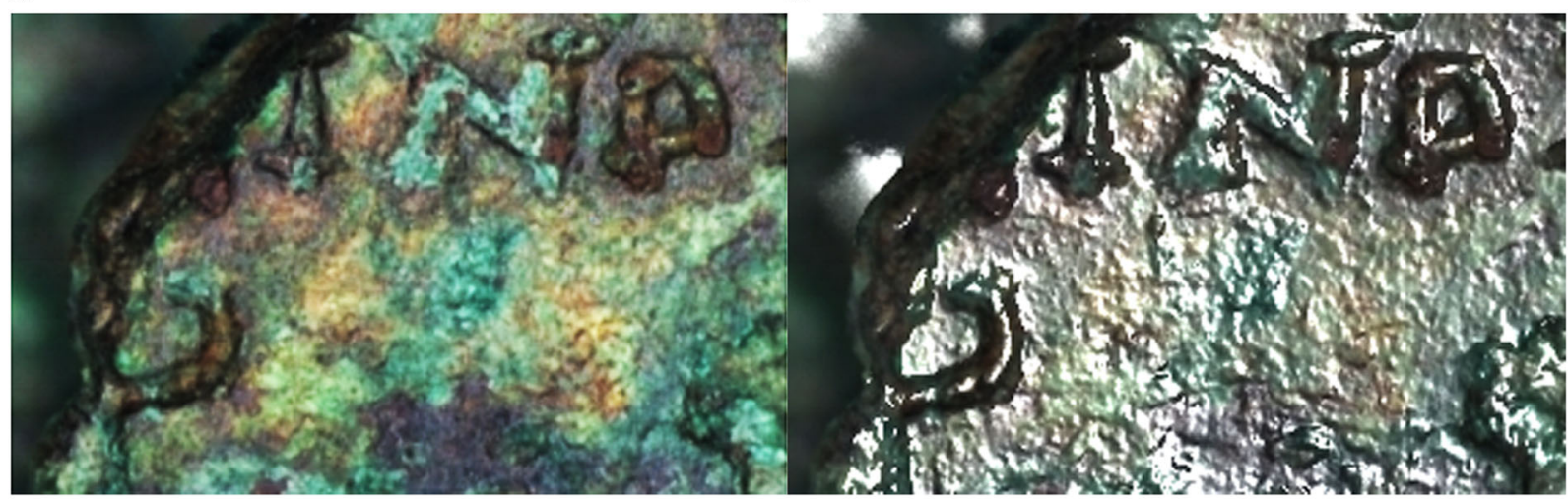

C

d

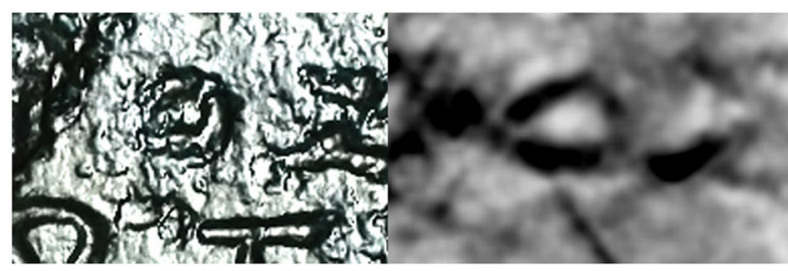

PTM data courtesy Hewlett-Packard 2005 e

f

(

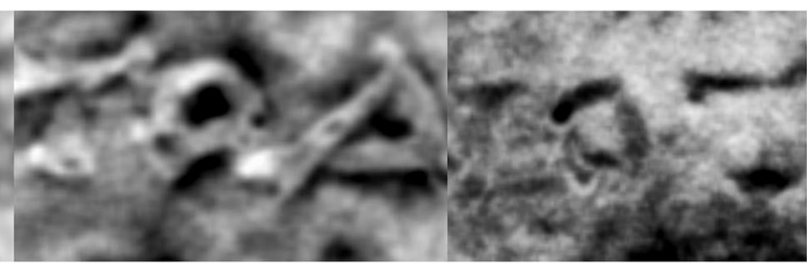

X-ray CT data courtesy X-Tek Systems 2005

Fig. 8 Examples of the character that looks like $o$ in the eclipse inscriptions. a, b Lines 3, 4 of the inscriptions in Fragment A, PTM AK50a: a with diffuse gain, $\mathbf{b}$ with specular enhancement. The text character in Line 4 can be seen in the bottom left: it is $1.5 \mathrm{~mm}$ high. a-f Other examples of o in the eclipse inscriptions: a and b Fragment A, PTM AK50a, L.3. c Fragment A, PTM AK50a, L.13. d Fragment F, X-ray CT, L.25. e Fragment F, X-ray CT, L.27. f Fragment F, X-ray CT, L.30. This figure is covered by the Creative Commons Attribution 4.0 International License. Reproduced with permission of Hewlett-Packard \& X-Tek Systems; copyright (C2005 Hewlett-Packard /X-Tek Systems, all rights reserved

The layout of the eclipse inscriptions on the back dial should be substantially altered. The final claim of Anastasiou et al. (2016) can now be put to rest. The substantial reorganization of the Back Plate inscriptions in Anastasiou et al. (2016) depends on proposed changes of the Index Letter Groups. This paper argues that these changes are not sustainable.

\section{Conclusions}

The issues discussed here determine the whole design of the Back Plate of the Antikythera Mechanism. In summary, this paper rejects the Anastasiou et al. (2016) scheme because:

- It is not supported by the X-ray CT data of L.29 and the PTM of L.4 of the eclipse inscriptions.

- It breaks the natural one-to-one correspondence between glyphs and their index letters.

- It produces an uncomfortable disparity in the number of glyphs in each Index Letter Group.

- It implies that just one of the 29 extant index letters were lower-case, whereas all the other known index letters and all the other $3000+$ normal text characters in the Antikythera Mechanism are upper-case.

- It destroys the natural mathematical symmetry in the layout of the eclipse inscriptions on the Back Plate of the Antikythera Mechanism.

It is difficult to place any credence in this scheme.

The positive outcome of Anastasiou et al. (2016) is that the traces of a new index letter have been observed just before 2 in L.29 of the eclipse inscriptions. The X-ray CT evidence persuasively supports this finding. According to the theory proposed in Freeth (2014), this should be the index letter for the last glyph round the Saros Dial, which is designated as ' 4 ' in that paper. It has not yet been found possible to identify a suitable symbol in classical texts.

As a consequence of the observations in Anastasiou et al. (2016), the above discussions have led to an interesting revision of the original Freeth (2014) scheme for the Index Letter Groups, which is shown in Fig. 7c. This revision changes some of the Index Letter Groups but retains the overall quasi-symmetrical design of the scheme. The character 4 has now been moved from Conj. Solar Group D to the L.29 Group. To even up the sizes of the groups, the character $\mathrm{X}_{1}$ in L.18 (for which there is no direct evidence) has been moved from the L.18 Group to Conj. Solar Group D. The resulting scheme has a regular distribution: 4-5-44-6-5. The group with six eclipses includes those, which are Nearly at node-both North and South. This might explain why it is slightly bigger than the other groups. None of this changes the essential layout of the inscriptions, published in Freeth (2014). The consequences for the design of the Back Plate are shown in Figs. 1, 3, 4. This scheme is faithful both to the evidence and to the essentially mathematical conception of the remarkable eclipse prediction scheme on the Antikythera Mechanism.

\section{Data availability}

The datasets generated and analysed during the current study are available in the Harvard Dataverse repository: https://doi.org/ 10.7910/DVN/GKYKOV.

This material includes:

- AK49a.ptm: Polynomial Texture Mapping, PTM49a, of Line 9 from Fragment A of the Antikythera Mechanism, as seen in Fig. 5. - AK50a.ptm: Polynomial Texture Mapping, PTM50a, of Lines 3, 4 from Fragment A of the Antikythera Mechanism, as seen in Fig. 8. - F1 X-ray CT 10 microns INSCRIPTIONS: An X-ray image stack of all the inscriptions in Fragment $F$ of the Antikythera Mechanism, saved as a series of JPEG images, spaced 10 
microns apart. This includes Lines 19-36 of the eclipse inscriptions, as seen in Fig. 6.

- F1 X-ray CT 10 microns L29 CLOSE: An X-ray image stack of a region-of-interest (roi) of Fragment $F$, saved as a series of JPEG images, spaced 10 microns apart. This includes Line 29 of the Antikythera eclipse inscriptions, as seen in Fig. 6.

Received: 28 September 2018 Accepted: 10 December 2018 Published online: 22 January 2019

\section{References}

Anastasiou M, Seiradakis JH, Carman CC, Efstathiou K (2014) The Antikythera Mechanism: The Construction of the Metonic Pointer and the Back Plate Spirals. Journal for the History of Astronomy 45:418-441

Anastasiou M, Bitsakis Y, Jones A, Steele JM, Zafeiropoulou M (2016) Paper 4: the back dial and back plate inscriptions, the inscriptions of the Antikythera mechanism. Almagest. https://www.brepolsonline.net/doi/10.1484/J.ALMAGEST.5.110735

Freeth T et al. (2006) Decoding the ancient Greek astronomical calculator known as the Antikythera Mechanism Nature 444:587-591. http://www.nature.com/ nature/journal/v444/n7119/extref/nature05357-s1.pdf

Freeth T, Jones A, Steele JM, Bitsakis Y (2008) Calendars with Olympiad display and eclipse prediction on the Antikythera mechanism Nature 454:614-617. http://www.nature.com/nature/journal/v454/n7204/extref/nature07130-s1.pdf

Freeth T (2014) Eclipse prediction on the ancient Greek astronomical calculating machine known as the Antikythera Mechanism. PLOS ONE. https://doi.org/ 10.1371/journal.pone.0103275

Jones A (2017) A portable cosmos: revealing the Antikythera mechanism, scientific wonder of the ancient world. Oxford University Press, Oxford, UK

Hadland R et al. (2006) Antikythera Mechanism research investigations: the X-ray Computed Tomography inspection. https://www.nikonmetrology.com/en-gb/ search-results? $\mathrm{q}=$ antikythera $\& \mathrm{f}=1 \& 4741232$ edefeae7ae58e31c625b43b12 $=$. Accessed 09 Jan 2019

Price D de S (1975) Gears from the Greeks: the Antikythera mechanism: a calendar computer from ca. 80 BC. Trans Am Philos Soc New Ser 64:1-70

Malzbender T and Gelb D (2006) Antikythera Mechanism research investigations: polynomial texture mapping. http://www.hpl.hp.com/research/ptm/. Accessed 09 Jan 2019

Toomer GJ (1984) Ptolemy's Almagest. Duckworth, London

Wright MT (2002) A planetarium display for the Antikythera Mechanism. Horol J 144(5):169-173

Wright MT (2005) Epicyclic gearing and the Antikythera Mechanism, part II. Antiqu Horol 29:2
Wright MT (2006) The Antikythera Mechanism and the early history of the moon phase display. Antiqu Horol 29:319-329

\section{Acknowledgements}

The PTM data is published courtesy of Hewlett-Packard and the X-ray CT data courtesy of X-Tek Systems (Nikon Metrology). We thank them for their permissions to use the data. Equipment loaned by X-Tek Systems Ltd (now owned by Nikon Metrology) was used to collect the X-ray data. For the data gathering in 2005, great thanks are due to N. Kaltsas and his team of staff and conservators at the National Archaeological Museum in Athens, T. Malzbender and his team of imaging experts from Hewlett-Packard, R. Hadland and his team of X-ray specialists from X-Tek Systems and the Anglo-Greek team of scientists, who made this possible. The data gathering and subsequent analysis, on which this current research depends, received essential funding from the Leverhulme Trust, the Walter Hudson Bequest, the University of Athens Research Committee, the National Bank of Greece Cultural Foundation, the J. F. Costopoulos Foundation and the A. G. Leventis Foundation. The research for this current paper was not funded. Many thanks to G. Schwendner (Wichita State University) for his input on the unusual text characters and to L. MacDonald (University College London) and A. Dacanalis (University College London) for very helpful comments on the text.

\section{Additional information}

Competing interests: The author declares no competing interests.

Reprints and permission information is available online at http://www.nature.com/ reprints

Publisher's note: Springer Nature remains neutral with regard to jurisdictional claims in published maps and institutional affiliations.

(c) (i) Open Access This article is licensed under a Creative Commons Attribution 4.0 International License, which permits use, sharing, adaptation, distribution and reproduction in any medium or format, as long as you give appropriate credit to the original author(s) and the source, provide a link to the Creative Commons license, and indicate if changes were made. The images or other third party material in this article are included in the article's Creative Commons license, unless indicated otherwise in a credit line to the material. If material is not included in the article's Creative Commons license and your intended use is not permitted by statutory regulation or exceeds the permitted use, you will need to obtain permission directly from the copyright holder. To view a copy of this license, visit http://creativecommons.org/ licenses/by/4.0/.

(C) The Author(s) 2019 